\title{
TESTE DE RECUPERABILIDADE DE ATIVOS PARA PEQUENAS E MÉDIAS EMPRESAS: UM ESTUDO EM EMPRESAS DO MUNICÍPIO DE SINOP-MT
}

\author{
Nome Lyss Paula de Oliveira \\ Instituição/Afiliação Universidade Federal de Mato Grosso \\ País Brasil \\ Contato principal para correspondência: Iysspaula@gmail.com \\ Nome Cáren Ernestina de Sousa Silva \\ Instituição/Afiliação Universidade do Estado de Mato Grosso \\ País Brasil
}

\section{RESUMO}

O estudo analisou o teste de recuperabilidade de ativos em Pequenas e Médias Empresas (PME) e sua conformidade com as normas e orientações contábeis vigentes. Os métodos de pesquisa envolveram levantamento bibliográfico, pesquisa de campo realizado por meio de entrevistas com cinco PME e análise do conteúdo coletado, com o propósito de obter informações sobre a aplicabilidade do teste de recuperabilidade. Os resultados evidenciaram que nenhuma das empresas entrevistadas está aplicando o teste, alegando uma suposta dificuldade e carência no suporte para sua correta compreensão, as evidências apresentadas mostram que muitos dos entrevistados confundem as determinações do teste com outros procedimentos contábeis. $\mathrm{O}$ estudo apresenta contribuições ao evidenciar a necessidade de atualização dos conhecimentos sobre o procedimento nas PME e ao evidenciar aos órgãos reguladores contábeis as dificuldades que essas empresas detém para seguir as práticas atuais. O estudo também trouxe contribuições teóricas ao abordar um assunto com escassez de literatura.

Palavras-chave: Teste de Recuperabilidade. Pequenas e Médias Empresas. Normas e Orientações Contábeis Vigentes.

\begin{abstract}
The study analyzed the impairment test of assets in Small and Medium Enterprises (SME) and their compliance with current accounting standards and guidelines. The research methods involved interviews, carried out with five SME, and analysis of the collected content, with the purpose of obtaining information about the applicability of the test of recoverability. The results showed that none of the companies interviewed are applying the test, claiming a supposed difficulty and lack in support for their correct understanding, the evidences presented show that many of the interviewees confuse the determinations of the test with other accounting procedures. The study presents contributions by highlighting the need to update knowledge about the procedure in SME and by showing the accounting regulatory agencies the difficulties these companies have to follow current practices. The study also brought theoretical contributions in addressing a subject with a shortage of literature.
\end{abstract}

Keywords: Recuperability test. Small and Medium Enterprises. Current Accounting Standards and Guidelines. 


\section{Contabilidade}

\section{INTRODUÇÃO}

A contabilidade no Brasil tem sido alvo de constantes mudanças em virtude da adoção das IFRS (International Financial Report Standards). Tendo como base as mudanças promovidas pelas IFRS o Conselho Federal de Contabilidade (CFC) adequa as normas brasileiras de contabilidade ao padrão internacional. O alcance das novas regras se deu pela Lei 11.638/07, inserindo o Brasil na adoção das práticas internacionais de contabilidade, este processo de adoção se deu tanto para companhias de capital aberto como para sociedades de grande porte.

Em consequência disso, devido ao grau de participação e relevância das pequenas e médias empresas em relação à economia nacional, houve a necessidade em se dispor de uma adaptação das normas internacionais de contabilidade às entidades de pequeno e médio porte. De acordo com dados divulgados pelo SEBRAE, no primeiro trimestre do ano de 2019 os pequenos negócios sustentaram a geração de empregos no Brasil (AGÊNCIA SEBRAE DE NOTÍCIAS, 2019).

No início de 2010 entrou em vigor a resolução 1.255/09 que estende a adoção das práticas internacionais de contabilidade às PME. Entende-se que até o surgimento da resolução, praticamente não havia esse tipo de cultura normalizadora contábil para as PME, assim sendo, não era um hábito a prática de certas exigências contábeis a essas empresas, sendo natural a reflexão de que as PME não estavam habituadas com ambiente de exigências societárias mais intensas e em virtude disso podem haver dúvidas e incertezas quanto aos procedimentos.

A partir dessa resolução o CFC aprovou a NBC T 19.41 - Contabilidade para Pequenas e Médias Empresas, que posteriormente foi alterada para NBC TG 1000, a qual constitui-se em um modelo simplificado de normas para as PME, emitido pelo Comitê dos Pronunciamentos Contábeis (CPC). Neste cenário de mudanças uma das ferramentas inclusa nas normas de contabilidade do Brasil foi o teste de recuperabilidade de ativos, passando a ser um instrumento que interfere na revelação do valor contábil disseminado aos usuários da contabilidade

Somente eram obrigadas a realizar o teste de recuperabilidade até o ano de 2009 as companhias de capital aberto e as sociedades de grande porte, logo a aprovação da resolução 1.225/09 estendeu a obrigação também para as PME. Desse modo, o teste de recuperabilidade deve ser realizado ao se suspeitar de uma redução no valor recuperável dos ativos, para ajustar seu Balanço Patrimonial e reflexos nos resultados, ou no encerramento do período (MENDES, 2011). Iudícibus et al. (2010, p. 243) afirmam que "umas das regras mais fundamentais da Contabilidade é a de que nenhum ativo pode ficar registrado contabilmente por mais do que 


\section{Revista

vale". Dessa forma o teste de recuperabilidade pode também ser considerado uma ferramenta estratégica, ao evidenciar a perda de valor de um ativo de forma mais acelerada do que se esperava, proporcionando informação contábil útil aos seus usuários interessados.

Em razão das eventuais mudanças no campo da contabilidade que as PME ficaram submetidas e da relevância da apresentação dos ativos ao seu valor recuperável, surge a necessidade de compreender as práticas que as PME adotaram para realizar a averiguação das perdas em recuperabilidade e o seu devido reconhecimento caso seja constatada a perda, bem como o nível de compreensão delas sobre a matéria em questão. Sendo assim surge a seguinte questão: As Pequenas e Médias Empresas do município de Sinop/MT estão realizando o teste de recuperabilidade de seus ativos, conforme determina as normas e orientações contábeis? Sendo objetivo do estudo, analisar se as PME do estudo estão realizando o teste de recuperabilidade de seus ativos, de acordo com o que preconiza as normas e as orientações contábeis vigentes.

O estudo se torna relevante ao apresentar contribuições no desenvolvimento de novas pesquisas sobre o teste de recuperabilidade de ativos, bem como por analisar práticas contábeis societárias em PME, campo atualmente com escassez de produção literária. Espera-se também apresentar contribuições práticas ao evidenciar os aspectos da aplicabilidade do teste de recuperabilidade de ativos nas PME e o nível de compreensão e esclarecimento dos gestores e profissionais contábeis atuantes nestas empresas sobre a norma, além de possibilitar um maior conhecimento no que diz respeito à adequação das normas contábeis internacionais nas pequenas e médias empresas brasileiras

\section{FUNDAMENTAÇÃO TEÓRICA}

\subsection{Teste de Recuperabilidade de Ativos}

O teste de recuperabilidade consiste no cálculo do valor recuperável do ativo e sua comparação com o valor contábil líquido, se houver indicação que o valor recuperável foi superior ao valor contábil líquido, não haverá desvalorização do ativo. Se o valor recuperável do ativo for menor que o valor contábil líquido, deve ser reconhecida a perda (MENDES, 2011). 


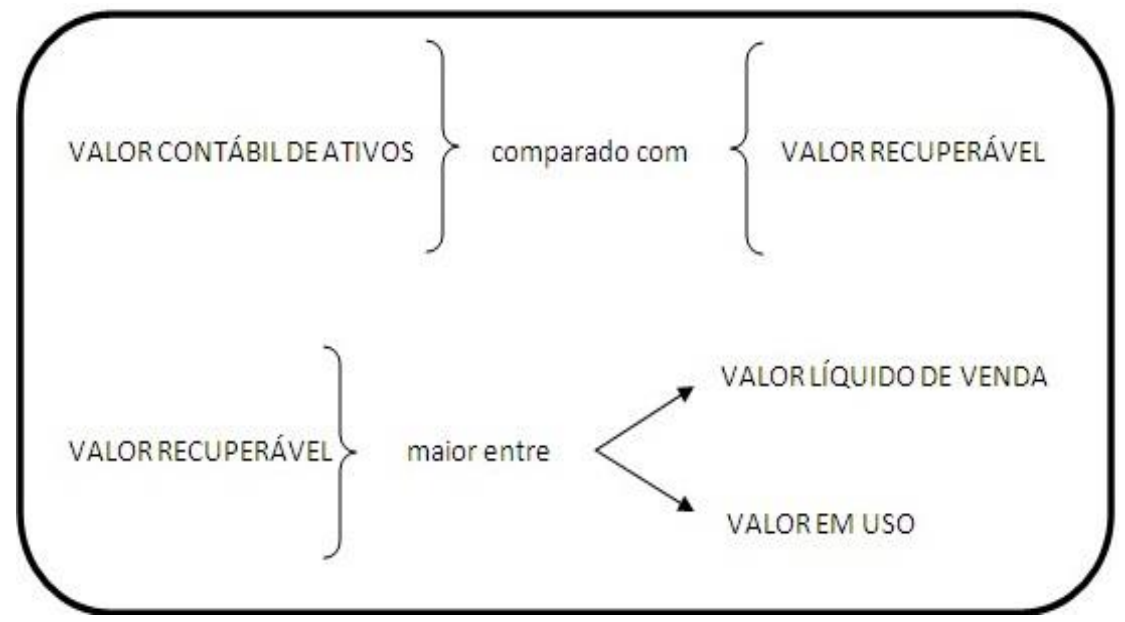

Figura 01: Comparação valor contábil com valor recuperável Fonte: adaptado do CPC (2011)

O objetivo do teste de recuperabilidade é fazer com que as empresas demonstrem seus ativos ao valor mais próximo da realidade realizável, ou seja, o teste de recuperabilidade busca comparar o valor contábil com o recuperável, onde prevalece o de menor valor (BRASIL ESCOLA DE NEGÓCIOS - BLB, 2016). De acordo com Silva et al. (2006, p.2) o teste de recuperabilidade, que também é conhecido internacionalmente como impairment test, "é um instrumento utilizado para adequar o ativo a sua real capacidade de retorno econômico".

De acordo com Ferrarezi e Smith (2008 apud PROVENSI, 2013, p. 16), "é importante observar que a existência, apuração e registro do impairment podem refletir significativamente no resultado do exercício e nos valores dos ativos que serão reduzidos aos valores recuperáveis". Após o teste de recuperabilidade é reconhecida a perda por impairment e o valor das despesas com depreciação, amortização ou exaustão, o qual deve ser ajustado nos próximos períodos para alocar o valor contábil ao longo de sua vida útil remanescente (LEMES; CARVALHO, 2010).

O CPC da PME e a NBC TG 1000 determinam ainda que nos ativos descontinuados ou disponíveis para a venda, a perda por impairment deve ser reconhecida pelo seu valor de mercado ou pelo valor de ativos similares, ou seja, pelo valor líquido de venda. Portanto, é necessário que a cada ano as empresas avaliem a recuperabilidade dos valores registrados em seu ativo, o que implica que o valor contábil desses ativos seja limitado ao seu valor econômico. 


\subsection{As Pequenas e Médias Empresas na Visão dos Órgãos Contábeis}

De acordo com o International Accouting Standard Board ${ }^{1}$ (IASB) as pequenas e médias empresas são entidades que não tem obrigação a prestação pública de contas e que publicam demonstrações financeiras para fins gerais. O Conselho Federal de Contabilidade acompanha o entendimento do IASB frente as pequenas e médias empresas estabelecendo que elas não têm obrigação pública de prestação de contas e elaboram demonstrações contábeis para fins gerais a usuários externos (CFC, 2012).

O conceito de pequenas e médias empresas não é um consenso padronizado no universo dos negócios, de acordo com o SEBRAE (2013) o entendimento frente ao porte da empresa se dá conforme o número de colaboradores que são empregados no negócio. A visão normativa contábil porém estabelece outra forma para classificação das empresas na determinação de seu porte.

O critério instituído por meio da Lei 11.638/2007, determina que para fins contábeis societários considera-se grande empresa aquelas entidades que auferiram receita anual igual ou superior a R \$ 300 milhões e/ou possuírem ativos iguais ou superiores a R \$ 240 milhões. Deste modo, as entidades que não alcançam esses patamar pré-estipulados são consideradas micro, pequenas ou médias empresas.

A adoção das IFRS-PME não é um exercício meramente técnico, envolvendo o reordenamento de informações nas demonstrações contábeis. A adoção das IFRS-PME irá desafiar os fundamentos de um modelo de negócios até então inexistente nas pequenas e médias empresas, fornecendo a elas uma oportunidade para reexaminar sua gestão, por meio da maneira de elaborar seus relatórios internos (SILVA, 2011).

De acordo com o IASB, o objetivo das IFRS-PME é oferecer informações sobre a posição financeira da entidade, sendo úteis nas tomadas de decisões econômicas para os usuários que não estão em posição de exigir relatórios sob sua medida, para satisfazer suas necessidades particulares de informação (IASB, 2009).

\subsection{NBC TG 1000 e CPC PME - Redução ao Valor Recuperável de Ativos}

A contabilidade para as pequenas e médias empresas torna-se importante quando o gestor fica satisfeito com os resultados, quando passa a ver a contabilidade como uma

\footnotetext{
${ }^{1}$ Tradução: Comitê de Normas Internacionais de Contabilidade.
} 


\section{Revista \\ UNEMAT de \\ Contabilidade}

ferramenta gerencial e não como uma obrigatoriedade, sendo uma forma de auxiliá-los nos processos decisórios da empresa (LEMES; CARVALHO, 2010).

É por meio do grau de importância que a contabilidade tem para as PME, que o Conselho Federal de Contabilidade se preocupa em atualizar as informações necessárias para os gestores e os usuários. E através destas preocupações em atualizar as informações que disponibilizou a norma especial para as PME, a NBC TG 1000 (CFC, 2016).

A NBC TG 1000 - Contabilidade para pequenas e médias empresas, decorre da conversão em norma pelo Conselho, do Pronunciamento Técnico PME - Contabilidade para Pequenas e Médias Empresas, do Comitê de Pronunciamentos Contábeis, elaborado com base na IFRS-PME. Criada exclusivamente para as PME teve sua primeira revisão aprovada e publicada pelo CFC em 2016, com efeitos valendo a partir de $1^{\circ}$ de janeiro de 2017 (CFC, 2016).

No Brasil o Pronunciamento Técnico denominado Contabilidade para Pequenas e Médias Empresas - CPC-PME, entrou em vigor por meio da Resolução nº 1.255/09 deliberando que a partir de $1^{\circ}$ de janeiro de 2010, as empresas já se adequassem ao Pronunciamento e instituindo a NBC TG 1000. Tendo como objetivo simplificar e uniformizar o processo de convergência das normas contábeis brasileiras aplicadas às PME de acordo com as normas internacionais.

A NBC TG 1000 é um reflexo do elementos que foram tratados no CPC-PME, sendo assim, a partir deste ponto no texto será feita a menção ao CPC-PME com o entendimento da plenitude da NBC TG 1000. O CPC-PME está dividido em 35 seções, sendo uma delas exclusivamente endereçadas ao assunto redução ao valor recuperável de ativos, sendo ela a seção 27. A seção 27 dispõe ao tratamento contábil de redução ao valor recuperável de todos os ativos, exceto:

(a) tributos diferidos ativos;

(b) ativos provenientes de benefícios a empregados;

(c) ativos financeiros

(d) propriedade para investimento mensurada pelo valor justo

(e) ativos biológicos e produtos agrícolas relacionados com a atividade agrícola mensurados pelo valor justo menos as despesas estimadas de venda;

(f) ativos provenientes de contratos de construção.

O CPC PME (2011) menciona que a entidade deve avaliar em cada data de encerramento de exercício, se existe qualquer indicação de que um ativo possa estar desvalorizado. Se tal 
indicação existir, a entidade deve estimar o valor recuperável do ativo. Se não existir indicação de desvalorização, não é necessário estimar o valor recuperável.

Ao final, a entidade deverá divulgar as informações para cada classe de ativo, essas informações seriam o valor das perdas por desvalorização, a conta de resultado no qual essa perda foi incluída, o valor das reversões de perdas por desvalorização e a conta de resultado que essa perda foi inclusa (CPC PME, 2011).

O CPC PME tem como objetivo orientar as entidades a elaborar seus relatórios contábeis e fornecer uma base para solução dos problemas contábeis. Para que a empresa faça a adesão do pronunciamento, deverá oferecer junto aos demonstrativos, uma declaração evidenciando que está em conformidade com o referido pronunciamento (CPC PME, 2011).

Tratando-se das aplicações das normas internacionais da contabilidade nas pequenas e médias empresas, a IFRS para PME é um excelente modelo de prestação de contas para entidades menores, por ser mais adaptável ao seu porte de operações e sua estrutura societária, além disto, o padrão contribuirá para melhorar a qualidade e a comparabilidade das demonstrações financeiras das PME em todo o mundo (DELOITTE, 2010).

\section{MÉTODOS DE PESQUISA}

\subsection{Escolha dos Métodos}

O trabalho trata-se, de uma pesquisa teórico-empírica que para sua realização foi necessário, além da revisão bibliográfica, uma abordagem à campo com o intuito de obter informações sobre o teste de recuperabilidade nas pequenas e médias empresas na cidade de Sinop-MT. A pesquisa possui características qualitativas e descritiva, aplicando-se como instrumentos de coleta de dados a técnica de entrevistas, com a intenção de descrever os fatos observados sem interferir neles.

No que se refere aos procedimentos metodológicos, fez-se o uso da pesquisa bibliográfica com o intuito de aprimorar e refinar o conhecimento sobre o tema em questão. Segundo Gil (2010, p. 29), “a pesquisa bibliográfica é elaborada em material já publicado”, enquanto Vergara (1998, p. 46), estabelece que "a pesquisa bibliográfica é o estudo sistematizado desenvolvido com base em material publicado em livros, revistas, jornais, redes eletrônicas, isto é, material acessível ao público em geral”.

Para o alcance do propósito de pesquisa aplicou-se a abordagem descritiva em que, segundo Gil (1999) busca “descrever as características de determinadas populações ou 
fenômenos ou o estabelecimento de relações entre as variáveis. Ela utiliza-se de técnicas padronizadas de coleta de dados".

\subsection{Instrumentos de Coleta de Dados}

Nesta etapa, foram feitas as coletas dos dados necessários para realização da pesquisa. O método selecionado para a coleta de dados fora por meio de entrevista.

A entrevista representa uma técnica a qual o pesquisador tem um contato mais direto com a pessoa. Recorre-se a uma entrevista "quando existe necessidade de obter dados que não podem ser encontrados em registros e fontes documentais, podendo estes, serem fornecidos por determinadas pessoas" (BRITTO JÚNIOR; FEREZ JÚNIOR, 2011, p.239).

Foram selecionadas 05 (cinco) empresas do município de Sinop-MT, que se enquadram no porte de PME, levando-se em consideração o ponto de vista contábil societário. A amostra foi do tipo intencional em virtude da impossibilidade em se abranger todas as empresas que compunha a população de pesquisa. Os nomes das empresas foram preservados, dessa forma foram classificados como: Empresa 01, Empresa 02, Empresa 03, Empresa 04 e Empresa 05.

Os entrevistados foram contatados previamente e se dispuseram a colaborar com a pesquisa, sendo eles(elas) gestores(gestoras) das empresas ou contador(a). A entrevista fora conduzida por meio de um roteiro com perguntas abertas, dando possibilidade e oportunidade do entrevistado acrescer informações que pudessem ter valor analítico. O roteiro de entrevista continha 14 perguntas e o tempo médio de cada entrevista foi de 30 minutos.

\subsection{Instrumentos de Análise dos Dados}

Após a coleta dos dados foi preciso transcrever as respostas obtidas nas entrevistas em sua íntegra, e para que fossem apresentadas de forma mais organizada, fora elaborado quadros com o auxílio da ferramenta Microsoft Word. Fora transcrito individualmente as respostas obtidas de cada empresa, organizadas nos quadros e posteriormente feita a análise de seu conteúdo questão por questão, contundo analisando o conjunto de respostas. 


\section{APRESENTAÇÃO DOS RESULTADOS}

\subsection{Dados das Entrevistas}

Os dados obtidos foram organizados e transcritos no Quadro 1, esses dados são as respostas dos entrevistados para cada uma das 14 (quatorze) perguntas efetuadas. O quadro está organizado da seguinte forma: primeiro dispõe-se a pergunta e em seguida as respostas de cada empresa.

Quadro 1 - Respostas dos entrevistados.

\begin{tabular}{|c|c|}
\hline \multicolumn{2}{|c|}{ Questão 01 - Na empresa existe algum mecanismo de atualização contábil? } \\
\hline Empresa 01 & $\begin{array}{l}\text { Sim. Cursos, seminários, atualização da legislação, oferecido por empresas de consultoria } \\
\text { especializadas. Surge demanda de atualização então a empresa procura esses cursos para } \\
\text { se atualizar. Consultoria on-line, todas as dúvidas recorre a ela. }\end{array}$ \\
\hline Empresa 02 & $\begin{array}{l}\text { Sim. Na parte fiscal assinatura de sites para suporte online. ECONET, cursos, seminários, } \\
\text { palestras. }\end{array}$ \\
\hline Empresa 03 & Sim. Participação em cursos e seminários. \\
\hline Empresa 04 & $\begin{array}{l}\text { Sim. A empresa costuma contratar pessoas especializadas na área de contabilidade, para } \\
\text { treinamentos de seus funcionários. }\end{array}$ \\
\hline Empresa 05 & $\begin{array}{l}\text { A empresa não desenvolve nenhum tipo de treinamento voltado para a área. Não se } \\
\text { preocupa com atualizações contábeis, devido ao escritório de contabilidade cuidar da parte } \\
\text { contábil da empresa. }\end{array}$ \\
\hline \multicolumn{2}{|c|}{$\begin{array}{l}\text { Questão } 02 \text { - Você conhece algum órgão responsável para treinamentos, cursos e/ou seminários voltados } \\
\text { para as atualizações contábeis? }\end{array}$} \\
\hline Empresa 01 & Sim. A ECONET, consultoria e Assessoria IOB. \\
\hline Empresa 02 & Sim. JK cursos, o próprio $C R C$. \\
\hline Empresa 03 & Sim. $C R C-M T$ e SESCON-MT \\
\hline Empresa 04 & Sim. $C R C-M T$. \\
\hline Empresa 05 & $\begin{array}{l}\text { Não conheço, pois nunca participei de treinamentos, cursos ou seminários voltados para a } \\
\text { atualização. }\end{array}$ \\
\hline \multicolumn{2}{|c|}{$\begin{array}{l}\text { Questão 03 - Você conhece o CPC/NBC TG que trata de contabilidade para pequenas e médias } \\
\text { empresas? }\end{array}$} \\
\hline Empresa 01 & Sei que existe superficialmente, mas não utilizo na prática. \\
\hline Empresa 02 & Não tenho conhecimento. \\
\hline Empresa 03 & Sim, NBC TG 1000. \\
\hline Empresa 04 & Sim, mas não sigo a norma. \\
\hline Empresa 05 & Já ouviu falar, mas não conheço. \\
\hline \multicolumn{2}{|c|}{$\begin{array}{l}\text { Questão } 04 \text { - Na empresa existem mais pessoas que conhecem sobre contabilidade para pequenas e } \\
\text { médias empresas de acordo com o padrão IFRS? Em média quantas pessoas? }\end{array}$} \\
\hline Empresa 01 & Sim, o contador e uma supervisora contábil. \\
\hline Empresa 02 & Sim, o contador e seus auxiliares. \\
\hline Empresa 03 & Sim, o contador e mais duas pessoas. \\
\hline Empresa 04 & $\begin{array}{l}\text { Somente as assistentes do financeiro, que são duas pessoas, responsáveis para repassar as } \\
\text { informações para a contabilidade. }\end{array}$ \\
\hline Empresa 05 & Não. \\
\hline \multicolumn{2}{|c|}{ Questão 05 - A contabilidade da empresa é terceirizada? } \\
\hline Empresa 01 & Não. \\
\hline Empresa 02 & Não. \\
\hline Empresa 03 & Sim. \\
\hline
\end{tabular}




\section{Contabilidade}

\begin{tabular}{|c|c|}
\hline Empresa 04 & Sim. \\
\hline Empresa 05 & Sim. \\
\hline \multicolumn{2}{|c|}{ Questão 06 - A empresa recebe informações sobre o teste de recuperabilidade de ativos? } \\
\hline Empresa 01 & $\begin{array}{l}\text { Sim, já fiz curso referente ao teste e num módulo de uma MBA em planejamento tributário } \\
\text { que estudou sobre o teste. }\end{array}$ \\
\hline Empresa 02 & Não. \\
\hline Empresa 03 & Não. \\
\hline Empresa 04 & Não. Pois nem o escritório de contabilidade tem conhecimento sobre o assunto. \\
\hline Empresa 05 & $\begin{array}{l}\text { A empresa não recebe informações sobre o teste, e nem o escritório de contabilidade sabe } \\
\text { dizer do que se trata. }\end{array}$ \\
\hline \multicolumn{2}{|c|}{ Questão 07 - Você sabe como se aplica o teste de recuperabilidade de ativos? } \\
\hline Empresa 01 & $\begin{array}{l}\text { Sim. Tenho que aperfeiçoar mais, através de cursos, de exemplos práticos, para que no } \\
\text { momento necessário possa estar atualizado para colocar em aplicação na contabilidade. }\end{array}$ \\
\hline Empresa 02 & Conheço somente o conceito através da internet. \\
\hline Empresa 03 & Sim, mas somente a teoria. \\
\hline Empresa 04 & Nunca ouvi falar. \\
\hline Empresa 05 & Não conheço. \\
\hline \multicolumn{2}{|c|}{$\begin{array}{l}\text { Questão } 08 \text { - Você considera o nível de conhecimento sobre o teste de recuperabilidade de ativos } \\
\text { satisfatório/adequado? }\end{array}$} \\
\hline Empresa 01 & Precisa ser melhorado. \\
\hline Empresa 02 & Não é satisfatório. \\
\hline Empresa 03 & $\begin{array}{l}\text { É preciso me aprofundar mais, o conhecimento sobre o tema não é satisfatório devido a } \\
\text { importância que ele tem para a empresa. }\end{array}$ \\
\hline Empresa 04 & Não é satisfatório, pois não conheço. \\
\hline Empresa 05 & Não é satisfatório pois não tenho conhecimento sobre o teste. \\
\hline \multicolumn{2}{|c|}{ Questão 09 - A empresa realiza o teste de recuperabilidade de ativos? } \\
\hline Empresa 01 & $\begin{array}{l}\text { Não. Não colocou em prática, mas estamos fazendo a atualização da contabilidade } \\
\text { societária através da constituição de uma empresa no ramo de atividade de holding não } \\
\text { financeira para no momento oportuno atualizar seu ativo. }\end{array}$ \\
\hline Empresa 02 & Não. \\
\hline Empresa 03 & Não. \\
\hline Empresa 04 & Não. \\
\hline Empresa 05 & Não. \\
\hline \multicolumn{2}{|c|}{ Questão 10 - Quais os critérios usados na realização do teste de recuperabilidade de ativos? } \\
\hline Empresa 01 & A empresa não realiza o teste. \\
\hline Empresa 02 & $\begin{array}{l}\text { A empresa não realiza o teste, porém para atualização do valor de seu ativo, faz pesquisas } \\
\text { no mercado e na internet. }\end{array}$ \\
\hline Empresa 03 & $\begin{array}{l}\text { Não realizamos o teste, mas sempre busco pesquisar o valor no mercado para atualizar seu } \\
\text { ativo, exemplo de um terreno ou um veículo. }\end{array}$ \\
\hline Empresa 04 & Nenhum critério, não realizamos o teste. \\
\hline Empresa 05 & $\begin{array}{l}\text { Nenhum, o critério para atualização do valor, além da depreciação e pesquisar qual o valor } \\
\text { do bem no mercado. }\end{array}$ \\
\hline \multicolumn{2}{|c|}{$\begin{array}{l}\text { Questão } 11 \text { - Se realiza o teste de recuperabilidade de ativos, existem dificuldades encontradas para seu } \\
\text { reconhecimento? Quais costumam ser estas dificuldades? }\end{array}$} \\
\hline Empresa 01 & Não realizo o teste. \\
\hline Empresa 02 & Não realizo o teste. \\
\hline Empresa 03 & Não realizo o teste. \\
\hline Empresa 04 & Não realizo o teste. \\
\hline Empresa 05 & Não realizo o teste. \\
\hline
\end{tabular}




\begin{tabular}{|l|l|}
\hline Questão 12 - Se não realiza o teste de recuperabilidade de ativos por qual ou quais razões não o faz? \\
\hline Empresa 01 & $\begin{array}{l}\text { Não fazemos por enquanto, pois a empresa está fazendo uma reforma na contabilidade } \\
\text { societária. Mas futuramente pretendemos fazer. }\end{array}$ \\
\hline Empresa 02 & Falta de conscientização da empresa. \\
\hline Empresa 03 & $\begin{array}{l}\text { Estamos nos atualizando contabilmente das novas normas, e futuramente pretende-se } \\
\text { aplicar o teste, mas no momento não fazemos. }\end{array}$ \\
\hline Empresa 04 & $\begin{array}{l}\text { Não faz, por falta de conhecimento, por não saber se era necessário, ou por não saber que } \\
\text { existia esse teste para atualização do ativo. }\end{array}$ \\
\hline Empresa 05 & Não faz, pois nunca ouvimos falar. \\
\hline \multicolumn{2}{|l|}{} \\
\hline Questão 13-A empresa está reconhecendo as perdas por não recuperabilidade de ativos? \\
\hline Empresa 01 & Não. \\
\hline Empresa 02 & Não. \\
\hline Empresa 03 & Não. \\
\hline Empresa 04 & Não. \\
\hline Empresa 05 & Não. \\
\hline \multicolumn{2}{|l|}{} \\
\hline Questão 14 - Existem dificuldades em compreender como é realizado o teste de recuperabilidade de \\
\hline Empresa 01 & Sim. \\
\hline Empresa 02 & Sim. \\
\hline Empresa 03 & Sim. \\
\hline Empresa 04 & Sim. \\
\hline Empresa 05 & Sim. \\
\hline
\end{tabular}

Fonte: Elaborado pelas autoras

Após a apresentação das respostas obtidas nas entrevistas, para cada uma das empresas em estudo, a seção a seguir contempla as discussões e análises inferidas a partir dos dados coletados.

\subsection{Análise dos Resultados}

Os dados coletados e apresentados no Quadro 1 evidenciam as dificuldades para compreensão do método contábil que testa a recuperabilidade dos ativos e sua falta de aplicabilidade por parte das empresas em estudo. As questões elaboradas para os entrevistados tinham como base, principalmente, observar se os gestores executivos ou contadores tinham conhecimento e prática sobre o teste e sobre a norma contábil vigente para pequenas e médias empresas.

Ao observar a respostas obtidas, constatou-se que o contador da Empresa 02 prioriza a atualização dos aspectos fiscais no desenvolvimento das atividades inerentes a contabilidade. É possível evidenciar que não foi demonstrada manifestação de interesse com os assuntos contábeis societários. Levando-se em consideração que a norma vigente para as PME trata da contabilidade em todos os seus aspectos, sendo dividida em 35 seções, é pertinente que as entidades atualizem-se referente aos procedimentos contábeis como um todo. 
Já o contador da Empresa 01 e os gestores das empresas 03 e 04 costumam participar de cursos, seminários e manter consultorias com a finalidade de suprir a demanda por atualização contábil. Contudo o gestor da Empresa 05 apontou não desenvolver nenhum tipo de atualização contábil, em razão de haver terceirizado os serviços contábeis da empresa e depositar nesse terceirizado a responsabilidade por atualizações.

Dentro do escopo abordado pelo gestor da Empresa 05, nota-se: para que o teste de recuperabilidade de ativos seja realizado de forma adequada em empresas com serviços contábeis terceirizados, deve existir uma harmonia entre a gestão da entidade e o profissional contábil, pois a ocorrência de perdas em recuperabilidade serão reconhecidos pela contabilidade, contudo é a empresa quem utiliza os benefícios econômicos gerados por esses ativos, assim sendo, será ela que poderá prestar informações relevantes no intuito de que a contabilidade aplique o teste de recuperabilidade adequadamente. A necessidade de conhecimento e aperfeiçoamento sobre as determinações do teste de recuperabilidade devem ser compartilhadas entre a entidade que reporta a informação e a sua gestão contábil.

No tocante ao conhecimento de órgão responsável em treinamentos, cursos e/ou seminários voltados para as atualizações contábeis, praticamente todas as empresas responderam que conhecem algum órgão, com destaque apenas para o gestor da Empresa 05 que respondeu não conhecer em virtude de nunca ter participado de treinamentos voltados à atualização contábil.

Existe uma falta de conhecimento sobre a norma contábil específica para PME apontada pelos respondentes. Levando-se em consideração que os entrevistados de quatro das cinco empresas estudadas, apontaram manter-se atualizados sobre normas contábeis, é possível relacionar que essas atualizações não estão alcançando a norma contábil em si. Mesmo as empresas que alegaram conhecer a norma, manifestam não a exercer no cotidiano das atividades. $\mathrm{O}$ conhecimento das normas societárias sobre recuperabilidade de ativos existe de forma teórica, mas não chega a ser aplicado.

Vale ressaltar que a norma está vigor há alguns anos. Logo após o seu período de vigor, os órgãos contábeis responsáveis permitiram um pouco mais de tempo para que as empresas e os escritórios contábeis se atualizassem e mesmo assim, o nível de conhecimento apontado pelos entrevistados é baixo.

Das empresas entrevistadas, três possuem a modalidade de contabilidade por serviços terceirizados e essas empresas alegam não receber informações dos escritórios contratados sobre o teste de recuperabilidade de ativos. As empresas 04 e 05 além de alegar não receber 


\section{Revista \\ UNEMAT de \\ Contabilidade}

informações, apontaram ter dúvidas sobre o nível de entendimento dos escritórios que assumiram a responsabilidade contábil da empresa sobre o assunto em questão, tornando evidente a falta de confiança que esses usuários detém nos profissionais contábeis contratados.

Com base nas respostas evidenciadas na questão 09 se confirmou que nenhuma das empresas entrevistadas realiza o teste de recuperabilidade de ativos, mesmo a maioria dos entrevistados tendo respondido que conhecem o teste. Porém, diante do fato de que os entrevistados alegaram conhecer apenas a teoria do procedimento, a resposta negativa para essa questão já era esperada. A consequência dessas evidências é o fato de que essas empresas podem estar apresentando demonstrativos contábeis a um valor contábil que não possam mais ser recuperados, o que faz com que a informação contábil perca a relevância ou venha a influenciar o processo de tomada de decisões dos usuários equivocadamente.

Um dos pontos mais conflitantes perante os dados coletados na pesquisa remonta a relação sobre critérios que seriam utilizados caso as entidades estivessem aplicando o teste de recuperabilidade de ativos. Como as respostas coletadas dos entrevistados foram negativas para realização do teste, esperava-se que os entrevistados respondessem não possuir critérios em função da ausência de execução do teste, contudo o contador da Empresa 02 alegou que atualiza o valor dos ativos tendo como base de mensuração pesquisas no mercado e buscas realizadas via rede mundial de computadores (internet).

Os gestores executivos das empresas 03 e 05, em sentido semelhante, também responderam atualizar o valor contábil dos ativos tendo como base valores de mercado. Neste ponto fica evidente uma distorção sobre o que vem a ser o teste de recuperabilidade de ativos, demonstrando que, mesmo o conhecimento teórico que muitos dos entrevistados alegaram ter sobre o procedimento contábil em destaque é falho.

A prática de atualização dos ativos a valor de mercado não é permitida para os ativos que são contemplados pelo teste de recuperabilidade de ativos. O valor de mercado compõe-se de um, dentre os três níveis do valor justo, estabelecidos pelo CPC 46, contudo, este CPC estabelece quais são os tipos de ativos e passivos que podem ser avaliados a valor justo.

O teste de recuperabilidade de ativos pressupõe reconhecimento de perdas caso elas sejam comprovadas pela aplicação de critérios adequados de estimativa do valor recuperável do ativo. Os entrevistados destacados, ao fazer menção a uma atualização de ativos a valor de mercado deixam dúvidas frente a que tipo de atualização eles costumam reconhecer, especialmente tendo em vista que a própria norma que versa sobre o teste de recuperabilidade 
atesta que, em casos de valor recuperável maior do que o valor contábil líquido, nada há a ser reconhecido.

O contador e os gestores das empresas apontadas devem observar que estão utilizando regras antigas e que mesmo na época em que estavam vigentes, critérios para a sua prática eram determinados. A consequência desta prática pode estar gerando inconsistências nas demonstrações contábeis. Destaca-se ainda que o Ministério da Fazenda - Secretaria da Receita Federal publicou no Processo de Consulta n ${ }^{\circ}$ 19/2009 que a partir de $1^{\circ}$ de janeiro de 2008, data de vigência da Lei $n^{\circ} 11.638 / 2007$, vedou-se às empresas a possibilidade de fazer, de forma espontânea, registros contábeis de reavaliação de ativos, figura que parece muito semelhante a prática descrita pelos entrevistados.

Por fim, os dados coletados evidenciaram que os entrevistados alegam não realizar o teste de recuperabilidade de ativos por falta de conhecimentos sobre a sua necessidade no âmbito contábil e gerencial, apontando existirem dificuldades em compreender efetivamente como o teste é realizado. Os entrevistados das empresas 01 e 03 evidenciaram estar promovendo adequações em sua estrutura contábil de modo a iniciar o processo de aplicação do teste de recuperabilidade de ativos.

\section{CONSIDERAÇÕES FINAIS}

O estudo originou-se da necessidade em se pesquisar a adequação das micro e pequenas empresas a aplicação das normas contábeis internacionais a sua realidade de negócios. Nesse contexto, o teste de recuperabilidade de ativos é uma das exigências que passaram a contemplar a contabilidade das PME com a divulgação do CPC-PME e da NBC TG 1000, sendo o centro deste estudo.

Após as análises realizadas identificou-se que as empresas entrevistadas no estudo não estão realizando o teste de recuperabilidade de seus ativos. As evidências apontadas levam a constatação de que as entidades, mesmo alegando deter o conhecimento teórico sobre a matéria, na realidade não tem um entendimento claro sobre a norma que versa a respeito do teste.

Um elemento apontado como razão para a não aplicação do teste fora a falta de compreensão sobre como ele é aplicado efetivamente. $\mathrm{O}$ estudo também constatou um distanciamento entre as entidades e os profissionais contábeis no tocante ao compartilhamento de informações relevantes à evidenciação da informação contábil nas empresas que terceirizaram suas demandas contábeis. 


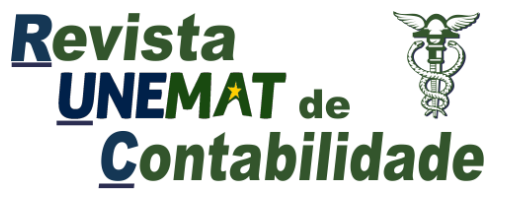

Um ponto crítico apresentado nos resultados do estudo remonta a distorção do que vem a ser o teste de recuperabilidade, de acordo com a norma preconizada, por parte de três dos entrevistados, levando a crer que técnicas não relacionadas estão sendo associadas ao que seria efetivamente o teste de recuperabilidade de ativos.

Os resultados encontrados trouxeram contribuições práticas ao evidenciar o não alcance da norma nestas entidades. Essas evidências levantam a questão de que outras PME também podem estar deixando de atender normas contábeis em razão da falta de compreensão prática do assunto. Os resultados levantam as seguintes reflexões: há uma necessidade de atualização dos conhecimentos sobre o procedimento nas PME; e os órgãos reguladores/normatizadores contábeis devem estar atentos às dificuldades que essas empresas têm para seguir as práticas determinadas atualmente. O estudo também trouxe contribuições teóricas ao abordar um assunto com escassez de literatura.

O estudo possui limitações reservando seus resultados ao seu número de amostra, sendo assim, os resultados aqui encontrados não podem ser associados a todas as PME. Sugerese, para futuras pesquisas, estudos que observem as ações praticadas pelos órgãos contábeis no tocante a orientações das práticas contábeis vigentes para as PME.

\section{REFERÊNCIAS}

AGÊNCIA SEBRAE DE NOTÍCIAS. Pequenos negócios sustentam a geração de empregos no início de 2019. SEBRAE. Disponível em: 〈https://agenciasebrae.com.br/>. Acesso em: 11 abr. 2019.

BRASIL ESCOLA DE NEGÓCIOS - BLB. CPC 01: Redução ao valor Recuperável de Ativos. Disponível em: <http://portal.blbbrasilescoladenegocios.com.br/>. Acesso em: 07 out. 2017.

BRITTO JÚNIOR, Á. F.; FERES JÚNIOR, N. A utilização da técnica da entrevista em trabalhos científicos. Disponível em: <http://uniaraxa.edu.br/>. Acesso em: 08 out. 2017.

BRASIL. Lei $\mathrm{n}^{\circ} 11.638$, de 28 de dezembro de 2007. Altera e revoga dispositivos da lei $n^{\circ} 6.404 / 1976$ e da Lei $n^{\circ} 6.385 / 76$, e estende às sociedades de grande porte disposições relativas à elaboração e divulgação de demonstrações financeiras. Diário Oficial da União, Brasília, DF, 28 dez. 2007. Disponível em: <http://www.planalto.gov.br/>. Acesso em: 23 jan. 2017.

BRASIL. Ministério da Fazenda - Secretaria da Receita Federal. Processo de Consulta ${ }^{\circ}$ 19/2009. Assunto: Imposto sobre a Renda da Pessoa Jurídica (IRPJ). Diário Oficial da União, Brasília, DF, 20 mar. 2009. Disponível em: 〈http://normas.receita.fazenda.gov.br/〉. Acesso em: 17 dez. 2017. 
COMITÊ DOS PRONUNCIAMENTOS CONTÁBEIS. CPC PME. Pronunciamento técnico PME - Contabilidade para pequenas e médias empresas. Pronunciamentos. Disponível em: <http://www.cpc.org.br/>. Acesso em: 10 out. 2017.

Resolução 2016/NBCTG1000(R1) Altera a NBC TG 1000 que dispõe sobre a contabilidade de pequenas e médias empresas. Disponível em: <http://www2.cfc.org.br/>. Acesso em: 10 out. 2017.

CONSELHO FEDERAL DE CONTABILIDADE. Contabilidade para pequenas e médias empresas: normas brasileiras de contabilidade: NBC TG 1000.2. ed. -- Brasília: Conselho Federal de Contabilidade, 2012.

CONSELHO FEDERAL DE CONTABILIDADE. Publica revisão de Norma de Pequenas e Médias Empresas. Disponível em: <http://cfc.org.br/>. Acesso em: 20 abr. 2017.

DELOITTE. IFRS para PMEs ao seu alcance: um guia para sua jornada rumo ao padrão contábil global. Disponível em: 〈http://www.deloitte.com.br/>. Acesso em: 17 out. 2017.

GIL, A. C. Método e técnicas de pesquisa social. 5.ed. São Paulo: Atlas, 1999.

GIL, A. C. Como Elaborar Projetos de Pesquisa. 5.ed. São Paulo: Atlas, 2010.

IASB - INTERNATIONAL ACCOUNTING STANDARDS BOARD.International Financial Reporting Standard (IFRS) for Small and Medium-sized Entities (SMEs). Disponível em: <http://eifrs.iasb.org/>. Acesso em: 13 abr. 2017.

IUDICIBUS, S.; MARTINS, E.; GELBCKE, E. R.; SANTOS, A. Manual de Contabilidade Societária: Aplicável a todas as sociedades de acordo com as normas internacionais e do CPC. São Paulo: Atlas, 2010.

LEMES, S.; CARVALHO, L. N. Contabilidade Internacional para Graduação: texto, estudos de caso e questões de múltipla escolha. São Paulo: Atlas, 2010.

MENDES, W. Contabilidade para pequenas e médias empresas (PMEs). 1.ed. São Paulo: IOB, 2011.

PROVENSI, A. Impacto do teste de recuperabilidade de Ativos na Análise das Demonstrações Financeiras. Trabalho de Conclusão, Universidade de Passo Fundo, Soledade, 2013. Disponível em: <http://repositorio.upf.br/>. Acesso em: 22 set. 2017.

SERVIÇO DE APOIO A MICRO E PEQUENA EMPRESA - SEBRAE. Definição de porte de estabelecimento segundo o número de empregados. Disponível em:

<https://m.sebrae.com.br/>. Acesso em: 11 abr. 2019.

SILVA, P. D. A.; CARVALHO, F. M.; DIAS, L. N. S.; MARQUES, J. A. V. C. Impairment de Ativos de Longa Duração: Comparação entre SFAS 144 e o IAS 36. Congresso EAC. USP. 2006. 
SILVA, R. C. Normas Internacionais de Relatórios Financeiros para Pequenas e Médias Empresas - IFRS-PME. Disponível em: <http://www.bdobrazil.com.br/>. Acesso em: 22 mai. 2017.

VERGARA, S. C. Projetos e Relatórios de Pesquisa em Administração. 2.ed. São Paulo: Atlas, 1998. 